\title{
Development and Validation of the Social Attunement Questionnaire (SAQ)
}

\author{
Emese Kroon ${ }^{1,2}$, Gabry Mies ${ }^{1,2,3}$, Reinout W. Wiers ${ }^{2,4}$ \& Janna Cousijn ${ }^{1,2,5}$ \\ ${ }^{1}$ Neuroscience of Addiction (NofA) Lab, Department of Psychology, University of Amsterdam, The Netherlands \\ ${ }^{2}$ ADAPT-laboratory, Department of Psychology, University of Amsterdam, the Netherlands \\ ${ }^{3}$ Karakter Child and Adolescent Psychiatry University Center, Nijmegen, The Netherlands \\ ${ }^{4}$ Centre for Urban Mental Health, University of Amsterdam, Amsterdam, the Netherlands \\ ${ }^{5}$ Department of Psychology, Education \& Child Studies, Erasmus University Rotterdam, The Netherlands
}

\begin{abstract}
Author Note
Correspondence: Emese Kroon, e.kroon@uva.nl, P.O. box 15916, 1001 NK Amsterdam, The Netherlands

Declarations of interest: none

Acknowledgements: We would like to thank the expert researchers and others that provided their constructive and valuable feedback to the first version of our social attunement questionnaire (SAQ).

Funding: This research was supported by grant 1R01 DA042490-01A1 awarded to Janna Cousijn from the National Institute on Drug Abuse/National Institute of Health.

Author contributions: All authors reviewed and approved the final version. Conceptualization: GM, JC and EK; Methodology: JC, GM and EK; Investigation: EK and GM; Formal Analysis: EK, GM, RW and JC; Data curation: EK, GM and JC; Writing - Original draft: EK; Writing - Review \& Editing: JC, GM and RW; Visualization: EK; Supervision: JC, GM and RW; Funding Acquisition: JC.
\end{abstract}

Data Accessibility: The data, code and materials of this study are available from the corresponding author upon reasonable request.

Preregistration: The study design and the analysis plans were not preregistered Preprint: this is a preprint version of this article which has not been peer-reviewed or published 


\section{Abstract}

The social plasticity hypothesis proposes that social attunement, i.e., the adaptation to and harmonization with one's environment, plays a crucial role in the risk for developing alcohol use disorders (AUDs) during adolescence, while in adulthood, it may paradoxically make individuals more sensitive to the social pull to reduce drinking. This study aimed to develop a valid measure of social attunement: the social attunement questionnaire (SAQ). A total of 26-items were developed and the questionnaire was completed by 576 participants over three rounds of online data collection. Using exploratory factor analysis in part of the sample $(N=373)$, the final questionnaire was reduced to two subscales with a total of 11 items. This structure was confirmed using confirmatory factor analysis in the second part of the sample $(N=203)$. Results showed that the SAQ has acceptable internal consistency, good measurement invariance to gender, and subscales assessing both cognitive as well as behavioural components of social attunement. In line with expectations on alcohol use settings, SAQ scores were not directly associated with alcohol use, but they were predictive of alcohol use when taking into account the interaction between perceived peer drinking and age. The SAQ appears suitable for the assessment of social attunement in (young) adult men and women, particularly assessing the role of social attunement in alcohol use settings. Further research is needed to confirm the utility of the SAQ in older adults and a broader variety of social settings.

Keywords: adolescent development, social attunement, questionnaire development, validation, alcohol use

\section{Public significance statement}

This study describes the development and validation of the social attunement questionnaire (SAQ) that was developed to assess an individual's adaptation and harmonization with the social environment. Results showed that the SAQ captures both the cognition and behaviour components of social attunement. Also, the SAQ showed good measurement invariance to gender and results are in line with our expectations of the role of social attunement in alcohol use situations. 


\section{Introduction}

Adolescent development is of great interest to multiple fields of research, including addiction research. It is characterized by major physical and social changes, and high social learning and brain plasticity make that adolescents are generally very flexible in adjusting to those changes (Cousijn, Luijten, \& Feldstein Ewing, 2018). At the same time, adolescents often show increased risk-taking (Crone \& Dahl, 2012). This attraction to risky behaviour is thought to be guided by a relative imbalance between the heightened sensitivity of fronto-limbic brain areas involved in affective learning and reward processing, and more protracted development of frontal areas guiding control over our actions (Casey, Jones, \& Hare, 2008; Gladwin, Figner, Crone, \& Wiers, 2011). As reward sensitivity is high and cognitive control suboptimal, immediate reward is preferred, while the long-term consequences of (risky) actions are largely ignored. This is also reflected in the often-seen excessive alcohol use in social situations during adolescence, which increases the risk of developing alcohol use disorders (AUDs; MacPherson, Magidson, Reynolds, Kahler, \& Lejuez, 2010). Nonetheless, most adolescents and young adults who drink excessively, and meet criteria for an AUD, go through a phase of natural reduction of use when maturing (Chassin, Flora, \& King, 2004; Vergés et al., 2013). This natural reduction, sometimes referred to as 'maturing out of addiction', might be partly caused by increased behavioural control, but this development does not fully explain why some adolescents maintain AUDs in adulthood and most naturally reduce use (Heyman, 2009).

Paradoxically, the same neuro-social mechanisms that place adolescents at initial risk for developing AUDs, might also result in a unique resilience to the maintenance of alcohol-related problems (Cousijn et al., 2018; Orford, 2001). More specifically, the social plasticity hypothesis describes how changing interactions between 1) (social) learning and (brain) plasticity, 2) behavioural control, and 3) social attunement could explain this increase and subsequent decrease in alcohol use seen in the transition from adolescence to adulthood (Cousijn et al., 2018). Social attunement, one of the concepts central to this social plasticity hypothesis, can be defined as the degree to which one adapts to and harmonizes with one's social environment (Cousijn et al., 2018). During adolescence, 
parental influence diminishes, whereas the need to socially attune to one's peers seems to increase (Marshal \& Chassin, 2000; Sebastian, Burnett, \& Blakemore, 2008). Attuning to one's peers can also affect adolescent alcohol use through perceived alcohol use norms within the peer group (e.g. BrooksRussell, Simons-Morton, Haynie, Farhat, \& Wang, 2014; Teunissen et al., 2012). Hence, adolescents prone to social attunement, who spend most of their time with an excessively drinking peer group, are hypothesized to show more excessive drinking behaviour, even in the absence of explicit peer pressure. Likewise, in a peer group with limited alcohol consumption, adolescents who are highly attuned to their environment are less likely to drink excessively.

The transition to adulthood involves major events like finishing studies, starting a job, finding a partner, and having children. During this maturation phase, group attitude regarding alcohol use often changes, resulting in social devaluation of alcohol use (Jackson, Sher, Gotham, \& Wood, 2001). It is hypothesized that individuals prone to social attunement, who were at risk for excessive drinking at first, will adapt to this change in alcohol's social value and reduce their alcohol use accordingly (Cousijn et al., 2018). Social attunement to the changing group norms might therefore be an important factor in the process of 'maturing out of addiction' (e.g. Dawson, Grant, Stinson, \& Chou, 2006; Lee, Ellingson, \& Sher, 2015). Due to high brain plasticity and flexible learning, adolescents and young adults are thought to be particularly good at attuning to those new group standards, even after periods of excessive use.

Although questionnaires on more negative reinforcing motives of behaviour change, such as social conformity (e.g. Mehrabian \& Stefl, 1995), have been developed over the years, there is no measure to assess social attunement yet. The difference in reinforcement motives guiding the behaviour makes it crucial to distinguish social attunement from social conformity behaviour. Where social conformity could be described as the behavioural adaptation to avoid negative feedback from the social environment (peer pressure/obedience - negative reinforcement), social attunement specifically explains behavioural adaptation to optimize and increase positive social feedback from this environment (positive reinforcement). Furthermore, this process might occur more implicit and 
gradual than conformity: as a result, over time one will start to resemble the individuals one spends the most time with, creating social harmony within the group. This behaviour will potentially be affected by the sensitivity of an individual towards the behaviour of others, and social attunement tendencies also depend on the differences between one's behaviour and the behaviour of the environment to attune to. Depending on the extent to which one values the behaviour of others, one will attune more or less to the behaviour of these individuals within the social group. This results in social harmony and increasingly positive socially rewarding outcomes (See Figure 1).

To test the social plasticity hypothesis (Cousijn et al., 2018), a valid instrument to measure social attunement is key. For this purpose, we developed and validated the social attunement questionnaire (SAQ). While the questionnaire was developed in the context of alcohol use and related problems, we aimed to develop a questionnaire that could also be used in other contexts (e.g. other substance use and social behaviours). We then assessed convergent and divergent validity of the SAQ and assessed measurement invariance to gender. SAQ scores were expected to be positively, but not one-on-one, associated with social conformity (Mehrabian \& Stefl, 1995), as similar responses to items that reflect behavioural outcome (change of behaviour and social reward) were expected, while social attunement and social conformity are supposed to diverge on items that reflect the motives and circumstances in which these behavioural outcomes occur. In addition, social attunement was expected to be positively associated with the pro-social interaction, admiration, and sociability subscale of the social reward questionnaire (Foulkes, Viding, McCrory, \& Neumann, 2014). On the other hand, no association was expected between social attunement and non-social behaviours such as need for cognition (Cacioppo \& Petty, 1982; non-social decision making) and the passivity and negative social potency subscales of the social reward questionnaires (non-pro-social behaviours).

Regarding the role of social attunement in alcohol consumption, we expected stronger social drinking motives (social and conformity) to relate to higher social attunement. Furthermore, we expected social attunement to decrease with age (Cousijn et al., 2018). As such, we expected social 
attunement to predict higher alcohol use especially in relatively younger participants and those who report relatively higher levels of peer alcohol use.

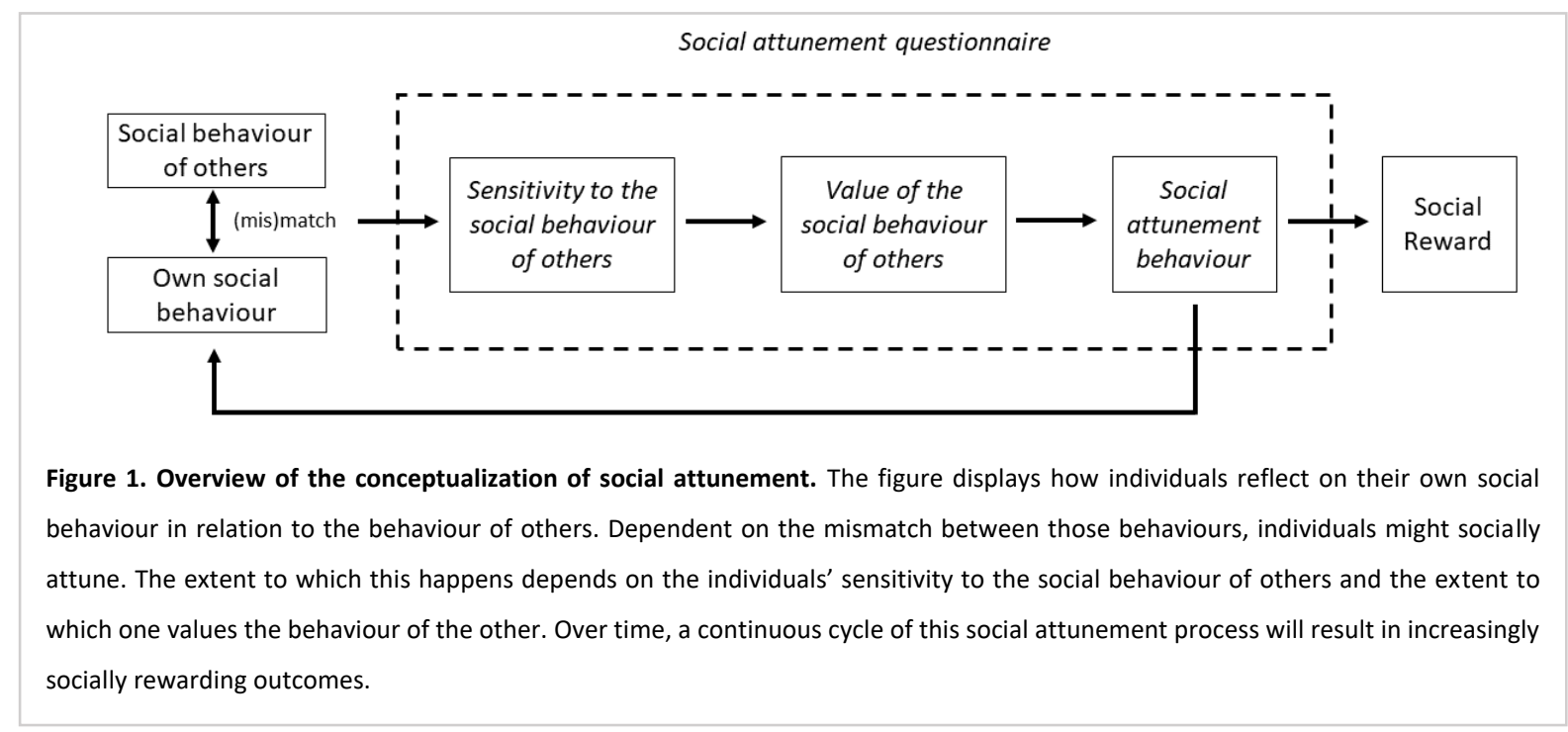

\section{Methods}

The development of the SAQ consisted of multiple phases including 1) item generation, 2) assessment of content and face validity, 3) online data collection for psychometric validation of the SAQ. In this third phase, we used exploratory factor analysis for item reduction and structure evaluation before assessing the internal consistency of the scale. Then, confirmatory factor analysis was performed to confirm the structure, internal consistency, and measurement invariance. Furthermore, convergent and divergent validity was evaluated and the association between social attunement, perceived peer drinking, and alcohol consumption was assessed. Methods were approved by the ethics committee of the psychology department of the University of Amsterdam (round 1 and 3: 2018-DP-8768, round 2: 2018-DP-9891), and participants in each phase were fully informed about the procedure and gave (online) consent before participation.

\section{Item Generation}

The following questionnaires on constructs related to social attunement were reviewed for initial item generation: Social Monitoring Scale (Lennox \& Wolfe, 1984; Mark Snyder \& Steve Grangestad, 1986), Concern for Appropriateness Scale (Lennox \& Wolfe, 1984), Need to Belong Scale (Leary, Kelly, Cottrell, \& Schreindorfer, 2013), and the Peer Pressure, Popularity, and Conformity Scale 
(Santor, Messervey, \& Kusumakar, 2000). A total of 23 items that, after adjustments, could fit the conceptualization of social attunement (Figure 1) were selected from the above-mentioned questionnaires (EK, checked by GM). These adjusted items were reviewed again (GM \& JC) to combine or delete items with overlapping content and the selection was supplemented with new items to make sure the included items covered all stages of our conceptualization, resulting in a total of 24 items.

\section{Content and face validity}

The first 24-item version of the SAQ was reviewed by 6 external experts in a relevant field (e.g. social learning or peer relations). These experts were provided with an explanation of our conceptualization of social attunement and asked to give their assessment of the relevance of each of the items item to the concept ("This item is relevant for the construct") and the clarity of each item ("This item is formulated clearly") on 7-point Likert scales (1=completely disagree, $7=$ completely agree), and to provide general feedback on the items. The average content validity index (CVI) for relevance, i.e. the percentage of positive ( 4 or higher) evaluations per item, was .88 (good; Polit $\&$ Beck, 2006). Two items with a CVI below .78 (sufficient; lowest CVI = .67; Polit \& Beck, 2006) were adjusted based on the provided feedback (EK) and re-assessed (GM \& JC). In addition to our group of experts, a group of 8 non-experts (variable age, sex, and educational level) were asked to answer the clarity question for all items. Clarity was assessed by averaging the scores per item across both experts and non-experts. Eight items (33.3\%) with an average score below 4 were adjusted based on provided feedback (EK) and re-assessed (GM \& JC). After re-evaluation of all items, two additional items were developed (EK) and reviewed (GM \& JC) with the aim of capturing the socially rewarding outcome (Figure 1) of social attunement.

\section{Psychometric evaluation of the SAQ}

\section{Participants}

A total of 589 responses on the SAQ were collected during 3 rounds of data collection (round $1: \mathrm{N}=196$, round $2: \mathrm{N}=182$, round $3=211$ ). Participants were recruited through social media (rounds $1 \& 3$ ), the lab website of the University of Amsterdam (rounds $1 \& 3$ ) or during the first-year 
psychology student test sessions held at the University of Amsterdam (round 2). Participants were compensated by receiving research credits (students in rounds 1, 2 and 3) or the opportunity to participate in a raffle for online gift cards (both students and non-students in rounds 1 and 3 ). Inclusion was based on age only and varied over rounds (round 1: 16-35, round 2: no limit, round 3: 16-80). Exclusion only applied to those who already participated in earlier rounds of the study.

\section{Measures}

\section{Item reduction and structure assessment}

The 26-item SAQ (Table 1) was used to assess social attunement on a 7-point Likert scale (1 = completely disagree, $2=$ disagree, $3=$ more or less disagree, $4=$ neutral, $5=$ more or less agree, $6=$ agree, 7 = Completely agree; see Table S1 for Dutch scale). Potential scores varied between 26 and 182 with higher scores indicating higher social attunement.

\section{Sample characteristics and measurement invariance}

Participants were asked to report on their age, gender (Round 1 and 3: male/female/other; Round 2: male/female), country of birth and highest completed level of education (low = primary education, pre-vocational secondary education, or vocational education; middle $=$ higher secondary education or higher professional education; high = pre-university secondary education or university) to be able to compare samples and assess measurement invariance.

\section{Convergent and divergent validity}

The need for cognition questionnaire (Round 1; Cacioppo \& Petty, 1982; Verplanken, Hazenberg, \& Palenéwen, 1992), social reward questionnaire (Round 1; Foulkes et al., 2014; items from the sexual reward subscale were ommited), and social conformity questionnaire (Round 3; Mehrabian \& Stefl, 1995) were included to assess convergent and divergent validity.

\section{Age, social attunement and alcohol consumption}

Participants completed the alcohol use disorder identification test (AUDIT; Saunders, Aasland, Babor, De la Fuente, \& Grant, 1993) to assess alcohol use and related problems, the Cooper's Drinking motives questionnaire (DMQ; Cooper, 1994) to assess drinking motives (i.e. social, conformity, coping 
,and enhancement), and a three-item adaptation of the first three items of the AUDIT to assess perceived peer drinking (PPD; See Table S2)

\section{Procedures}

After providing consent, participants completed basic demographic questions, followed by the 26-item SAQ, additional questionnaires to assess convergent and divergent validity, as well as questionnaires to assess the association between social attunement, perceived peer drinking, and alcohol use. In round 2, participants were compensated with research credit after participation as our questionnaires were included in a larger test-session organized by the University of Amsterdam. In rounds 1 and 3, all participants had the choice to leave their email address to participate in a raffle of six (three per round) 20-euro online gift cards. The raffle was performed after finishing data collection per round.

\section{Data analysis}

\section{Item reduction and structure assessment}

The data from rounds 1 and 2 were combined into sample $1(\mathrm{~N}=378)$ and the data from round 3 was used as sample $2(\mathrm{~N}=211)$, to create two sufficiently large samples for the planned analyses. Sample 1 was used for exploratory factor analysis and sample 2 for confirmatory factor analysis. Outliers, i.e., participants with SAQ sum scores \pm 2.5 SD from the mean were excluded from analyses. Using sample 1, exploratory factor analysis (EFA) was performed for item reduction and to assess the factor structure of the SAQ. The EFA was performed in JASP (JASP Team, 2020) using parallel analysis, principal axis factoring (accounting for violation of multivariate normality) and Promax rotation (because of the expected correlation between factors). Stepwise item reduction was guided by factor loadings, uniqueness, Kaiser-Meyer-Olkin $(\mathrm{KMO})$ criteria $(>.70=$ good), improved model fit, and additional conceptual considerations (see results section). Then, using the final factor structure, internal consistency for the full scale, as well as each subscale separately, was assessed using Cronbach's alpha (>.70 acceptable for scales with 10 or more items) and McDonald's Omega (>.70 acceptable). Using sample 2, confirmatory factor analysis (CFA), was performed to confirm the factor 
structure in an independent sample. Model fit was assessed using a chi-square test (significance indicating poor fit), as well as the comparative fit index (CFI; good fit above >.90), Tucker-Lewis index (TLl; good fit >.90) and Root Mean Square Error of Approximation (RMSEA; acceptable fit <.08, good fit <.05). Again, internal consistency for the full scale as well as each factor was assessed using Cronbach's alpha and McDonald's Omega (Hayes \& Coutts, 2020).

\section{Measurement invariance}

Gender differences in SAQ scores were assessed using an independent sample t-test (or Mann-Whitney $U$ test in case of violation of assumptions). To assess measurement invariance to gender, we ran the CFA again for both genders separately to check structure fit. Then, group CFA was performed assessing configural invariance, metric invariance, scalar invariance, and strict factorial invariance to gender.

\section{Convergent and divergent validity}

To assess convergent and divergent validity, we performed Pearson correlations (or Spearman correlations in case of violation of assumptions) between total SAQ as well as SAQ subscale scores, and the need for cognition questionnaire, social reward questionnaire, social conformity questionnaire, and age.

\section{Age, social attunement and alcohol consumption}

First, Pearson correlations (or Spearman correlations in case of violation of assumptions) between total SAQ scores and the four subscales of the DMQ, as well as age, PPD, and AUDIT score were assessed. Second, regression analyses were performed to assess whether SAQ score was predictive of AUDIT score and whether PPD, age and their interactions explained additional variance in this association.

\section{Data availability}

The data, code and materials of this study are available from the corresponding author upon reasonable request. 


\section{Results}

\section{Sample characteristics}

Sample 1 and sample 2 significantly differed on most demographics, with higher age, a higher percentage of females, and lower median completed education in sample 2 (Table 1). Looking at alcohol-related measures, perceived peer drinking and AUDIT score were higher in sample 1 and the samples differed on all drinking motives (Table 1).

\begin{tabular}{|c|c|c|c|c|}
\hline Measure & Sample 1 & Sample 2 & Statistics & p-value \\
\hline $\mathrm{N}$ & 373 & 203 & - & - \\
\hline Age, Med (range) & $20(16: 35)$ & $30(16: 78)$ & $U=23960.00$ & $<.001$ \\
\hline Gender, (Male/Female/Other\%) & $55.2 / 44.2 / 0.6$ & $29.6 / 70.4$ & $X^{2}(2, N=576)=36.73$ & $<.001$ \\
\hline Education, Med & 3 & 2 & $X^{2}(2, N=576)=158.09$ & $<.001$ \\
\hline Low (\%) & 3.75 & 33.99 & - & - \\
\hline Middle (\%) & 10.46 & 29.56 & - & - \\
\hline High (\%) & 85.79 & 36.45 & - & - \\
\hline SAQ Full, M (SD) & $46.8(5.5)$ & $43.0(8.3)$ & $t(574)=5.19$ & $<.001$ \\
\hline SAQ subscale $1, \mathrm{M}(\mathrm{SD})$ & $18.6(5.0)$ & $16.6(4.8)$ & $t(574)=4.81$ & $<.001$ \\
\hline SAQ subscale $2, \mathrm{M}(\mathrm{SD})$ & $28.2(5.2)$ & $26.5(5.5)$ & $t(574)=3.74$ & $<.001$ \\
\hline Need for Cognition, M (SD) ${ }^{1}$ & $63.8(9.3)$ & - & - & - \\
\hline SR-Admiration, Med (range) ${ }^{1}$ & $21(8: 28)$ & - & - & - \\
\hline SR-Negative Social Potency, Med (range) ${ }^{1}$ & $14(7: 35)$ & - & - & - \\
\hline SR-Passivity, Med (range) ${ }^{1}$ & $8(3: 21)$ & - & - & - \\
\hline SR-Pro-social interaction, Med (range) ${ }^{1}$ & $31(21: 35)$ & - & - & - \\
\hline SR-Sociability, Med (range) ${ }^{1}$ & $14(7: 21)$ & - & - & - \\
\hline Conformity, Med(range) & - & $0(-31: 22)$ & - & - \\
\hline Perceived peer drinking, Med (range) & $6(0: 11)$ & $5(1: 12)$ & $U=47800.00$ & $<.001$ \\
\hline AUDIT, Med (range) & $9(0: 26)$ & $6(1: 26)$ & $U=39621.00$ & $<.001$ \\
\hline DM-Conformity, Med (range) & $5(5: 25)$ & $5(5: 15)$ & $U=37222.50$ & $<.001$ \\
\hline DM-Social, Med (range) & $17(5: 25)$ & $13(5: 25)$ & $U=41464.50$ & $<.001$ \\
\hline DM-Coping, Med (range) & $7(5: 25)$ & $6(5: 19)$ & $U=33947.50$ & .016 \\
\hline DM-Enhancement, Med (range) & $15(5: 25)$ & $11(5: 21)$ & $U=41751.50$ & $<.001$ \\
\hline
\end{tabular}

\section{Exploratory factor analysis}

Exploratory factor analysis (EFA) was used for item reduction and the assessment of the structure of the SAQ. Assessment of KMO (Full scale $=.78$; Table 2 ) and the significance of Bartlett's test of sphericity $\left(X^{2}=757.085, \mathrm{df}=34, \mathrm{p}<.001\right)$ indicated adequacy of the data for EFA. 


\section{Item reduction}

Before running the first EFA, items 2, 8 and 19 were deleted. These items targeted social attunement in alcohol drinking situations specifically and, while originally included because of our interest in social alcohol drinking situations, were deleted to increase the generalizability of the measure for use in other social situations. Initial EFA, using parallel analysis, indicated a 5-factor structure (Table S3). Based on the initial EFA, items 7, 10, 15, 23 and 25 were deleted because of a lack of loading (> .3) on any of the factors (Table S3). The subsequent EFA, again, indicated a 5-factor structure (Table S3). Then, items 5 and 26 were deleted because of low KMO (KMO <.6). The third EFA resulted in a 2-factor structure with 2 (Table S3), followed by deleting items 1, 11, 16, 18, and 24 because of a lack of loading on any of the factors. The fourth EFA resulted in a final two-factor structure with 11 items (Table $2 \& 3$ ).

\begin{tabular}{|l|l|c|c|c|c|c|c|c|c|}
\hline \multicolumn{2}{|l|}{ Table 2. Overview of factor structure and item properties resulted from final exploratory factor analysis } \\
\hline $\begin{array}{l}\text { Item \# } \\
11 \text {-item }\end{array}$ & $\begin{array}{l}\text { Item \# } \\
26 \text {-item }\end{array}$ & Factor 1 & Factor 2 & MSA & Uniqueness & Mean & SD & Median & Range \\
\hline 2 & 4 & .55 & -.10 & .79 & .74 & 2.86 & 1.32 & 3 & $1: 7$ \\
\hline 3 & 6 & .53 & -.02 & .82 & .73 & 3.20 & 1.54 & 3 & $1: 7$ \\
\hline 5 & 12 & .63 & .13 & .74 & .51 & 5.00 & 1.37 & 5 & $1: 7$ \\
\hline 6 & 13 & .39 & .03 & .89 & .83 & 3.26 & 1.48 & 3 & $1: 7$ \\
\hline 8 & 17 & .78 & -.07 & .71 & .44 & 4.31 & 1.63 & 5 & $1: 7$ \\
\hline 1 & 3 & .15 & .56 & .79 & .58 & 4.20 & 1.55 & 5 & $1: 7$ \\
\hline 4 & 9 & -.07 & .43 & .76 & .84 & 4.31 & 1.49 & 5 & $1: 7$ \\
\hline 7 & 14 & -.00 & .68 & .77 & .54 & 4.62 & 1.52 & 5 & $1: 7$ \\
\hline 9 & 20 & .15 & .38 & .84 & .77 & 4.61 & 1.39 & 5 & $1: 7$ \\
\hline 10 & 21 & -.14 & .47 & .76 & .83 & 5.17 & 1.42 & 6 & $1: 7$ \\
\hline 11 & 22 & .14 & .35 & .87 & .81 & 5.28 & 1.05 & 5 & $2: 7$ \\
\hline Subscale 1 & - & - & - & - & - & 18.62 & 4.98 & 19 & $6: 30$ \\
\hline Subscale 2 & - & - & - & - & - & 28.19 & 5.17 & 29 & $12: 40$ \\
\hline Full scale & - & - & - & .78 & - & 46.80 & 8.42 & 47 & $22: 67$ \\
\hline Note: rotation method applied is promax. Only factor loading >.30 are presented. N = 373 & & & 5 \\
\hline
\end{tabular}

\section{Final structure}

While chi-square test of model fit was significant $\left(X^{2}(34, N=373)=92.991, p<.001\right)$, additional fit indices indicated an acceptable to good fit (RMSEA $=.069 ; \mathrm{TLI}: .86$ ). As expected, there was a 
substantial correlation between subscales 1 and $2(r=.62)$, but the items included in both subscales seemed conceptually distinct. Items of subscale 1 reflect social attunement related 'Cognitions', that is, the extent to which you think about your own behaviour and how others perceive your behaviour. Items of subscale 2, on the other hand, reflect actual social attunement related 'Behaviour', that is, the extent to which you adjust your behaviour to attune to the behaviour of others.

\section{Internal consistency}

Both factors showed acceptable internal consistency for subscale 1 (McDonald's Omega $=.71$, Cronbach's Alpha $=.71)$ and moderate internal consistency for subscale 2 (McDonald's Omega $=.67$, Cronbach's Alpha $=.66)$. Although higher internal consistency would be preferable, the limited

\begin{tabular}{|c|c|c|c|}
\hline $\begin{array}{l}\text { Item \# } \\
\text { 11-item }\end{array}$ & Item & $\begin{array}{l}\text { Item \# } \\
\text { 26-item }\end{array}$ & Factor \\
\hline 1 & $\begin{array}{l}\text { Ik gedraag mij weleens op een manier die niet echt bij mij past omdat dit beter aansluit op de } \\
\text { situatie. }\end{array}$ & \multirow[t]{2}{*}{3} & \multirow[t]{2}{*}{2} \\
\hline ENG & I sometimes behave differently from how I normally would, because it suits the situation better. & & \\
\hline 2 & Ik heb er geen probleem mee om anders te zijn dan de mensen in de groep waarin ik me bevind. (R) & \multirow[t]{2}{*}{4} & \multirow[t]{2}{*}{1} \\
\hline ENG & I do not have a problem with being different from the people in the group I am in. & & \\
\hline 3 & Ik probeer te voorkomen dat anderen denken dat ik anders ben. & \multirow[t]{2}{*}{6} & \multirow[t]{2}{*}{1} \\
\hline ENG & I try to prevent people from thinking that I am different. & & \\
\hline 4 & Ik neem vaak woorden van een ander over. & \multirow[t]{2}{*}{9} & \multirow[t]{2}{*}{2} \\
\hline ENG & I often adopt words into my vocabulary that I hear others using. & & \\
\hline 5 & Ik hecht veel waarde aan hoe mensen over mij denken. & \multirow[t]{2}{*}{12} & \multirow[t]{2}{*}{1} \\
\hline ENG & It really matters to me what people think of me. & & \\
\hline 6 & Als de meerderheid van een groep een bepaalde mening heeft, ga ik daar meestal in mee. & \multirow[t]{2}{*}{13} & \multirow[t]{2}{*}{1} \\
\hline ENG & When the majority of a group has a certain opinion, I usually agree. & & \\
\hline 7 & In verschillende situaties met verschillende mensen gedraag ik mij anders. & \multirow[t]{2}{*}{14} & \multirow[t]{2}{*}{2} \\
\hline ENG & In different situations with different people, I often behave very differently. & & \\
\hline 8 & Het kan mij weinig schelen wat anderen van mij vinden. (R) & \multirow[t]{2}{*}{17} & \multirow[t]{2}{*}{1} \\
\hline ENG & I do not care much about what others think of me. & & \\
\hline 9 & Als ik niet goed weet hoe ik me moet gedragen, kijk ik naar wat anderen doen. & \multirow[t]{2}{*}{20} & \multirow[t]{2}{*}{2} \\
\hline ENG & When I do not know how to behave, I look at what others do. & & \\
\hline 10 & Ik pas mijn taalgebruik aan aan mijn gezelschap. & \multirow[t]{2}{*}{21} & \multirow[t]{2}{*}{2} \\
\hline ENG & I adjust my language to who I am with. & & \\
\hline 11 & Ik probeer zo goed mogelijk aansluiting te vinden bij de groep waarin ik mij bevind. & \multirow[t]{2}{*}{22} & \multirow[t]{2}{*}{2} \\
\hline ENG & I try to align myself as good as possible to the group I'm with. & & \\
\hline \multicolumn{4}{|c|}{$\begin{array}{l}\text { Note: Participants were asked to answer using a 7-point likert scale (English: } 1=\text { Completely disagree, } 2=\text { disagree, } 3=\text { more or less } \\
\text { disagree, } 4=\text { neutral; ; } 5=\text { more or less agree, } 6=\text { agree, } 7=\text { Completely agree; Dutch: } 1=\text { helemaal mee oneens, } 2=\text { oneens, } 3=\text { een } \\
\text { beetje mee oneens, } 4=\text { neutral, } 5=\text { een beetje mee eens, } 6=\text { mee eens, } 7=\text { helemaal mee eens) and all items followed by (R) are reverse } \\
\text { coded items; ENG = English translation (included here for clarification purposes only). }\end{array}$} \\
\hline
\end{tabular}


number of items might negatively affect internal consistency (e.g. Taber, 2018). Looking at the full scale, internal consistency was acceptable (McDonald's Omega $=.75$, Cronbach's Alpha $=.75$ ).

\section{Confirmatory factor analysis}

Confirmatory factor analysis (CFA) was used to assess the consistency of the 11-item twofactor questionnaire structure in another sample (Sample 2; Table 1). The chi-squared test of model fit was not significant $\left(X^{2}(43, N=203)=58.781, p=.055\right)$, fit indices indicate that model fit was acceptable to good $(\mathrm{RMSEA}=.04, \mathrm{TLI}=.93, \mathrm{CFI}=.95)$ and factor covariance $(\operatorname{cov}=.41, \mathrm{SE}=.08, \mathrm{p}<$ .001) showed sufficient discriminant validity between the factors.

\section{Internal consistency}

Assessment of the internal consistency of both subscales in sample 2, showed moderate internal consistency for subscale 1 (McDonald's Omega $=.67$, Cronbach's Alpha $=.64)$, subscale 2 (McDonald's Omega $=.65$, Cronbach's Alpha $=.64)$, and the full scale (McDonald's Omega $=.67$, Cronbach's Alpha $=.69)$.

\begin{tabular}{|l|l|l|l|l|l|l|l|l|l|l|}
\hline \multicolumn{2}{|l|}{ Table 4. Confirmatory factor analysis results } \\
\hline $\begin{array}{l}\text { Item \# } \\
\text { 11-item }\end{array}$ & $\begin{array}{l}\text { Item \# } \\
\mathbf{2 6 - i t e m ~}\end{array}$ & Factor & Estimate & SE & Z-value & p-value & Mean & SD & Median & Range \\
\hline 2 & 4 & 1 & .40 & .09 & 4.31 & $<.001$ & 2.52 & 1.22 & 2 & $1: 7$ \\
\hline 3 & 6 & 1 & .59 & .13 & 4.70 & $<.001$ & 2.97 & 1.66 & 2 & $1: 7$ \\
\hline 5 & 12 & 1 & .31 & .12 & 11.33 & $<.001$ & 4.43 & 1.53 & 5 & $1: 7$ \\
\hline 6 & 13 & 1 & .39 & .11 & 3.63 & $<.001$ & 2.86 & 1.40 & 2 & $1: 7$ \\
\hline 8 & 17 & 1 & .14 & .12 & 9.48 & $<.001$ & 3.78 & 1.62 & 4 & $1: 7$ \\
\hline 1 & 3 & 2 & .81 & .14 & 5.84 & $<.001$ & 4.07 & 1.73 & 5 & $1: 7$ \\
\hline 4 & 9 & 2 & .48 & .13 & 3.77 & $<.001$ & 3.74 & 1.56 & 4 & $1: 7$ \\
\hline 7 & 14 & 2 & .93 & .12 & 7.90 & $<.001$ & 4.62 & 1.49 & 5 & $1: 7$ \\
\hline 9 & 20 & 2 & .95 & .13 & 7.57 & $<.001$ & 4.15 & 1.58 & 5 & $1: 6$ \\
\hline 10 & 21 & 2 & .65 & .13 & 5.18 & $<.001$ & 4.98 & 1.54 & 5 & $1: 7$ \\
\hline 11 & 22 & 2 & .61 & .10 & 5.92 & $<.001$ & 4.90 & 1.29 & 5 & $2: 7$ \\
\hline Subscale 1 & - & - & - & - & - & - & 16.56 & 4.78 & 17 & $5: 29$ \\
\hline Subscale 2 & - & - & - & - & - & - & 26.46 & 5.53 & 28 & $12: 39$ \\
\hline Full scale & - & - & - & - & - & - & 44.59 & 8.82 & 46 & $20: 69$ \\
\hline Note: SE: standard error, SD: standard deviation; N = 203 & & & & & & & \\
\hline
\end{tabular}




\begin{tabular}{|c|c|c|c|c|c|c|c|c|c|}
\hline Subgroup & $X^{2}$ & $D f$ & p-value & RMSEA & $90 \% \mathrm{Cl}$ & $\Delta$ RMSEA & p-value ${ }^{1}$ & CFI & $\Delta \mathrm{CFI}$ \\
\hline Men & 78.68 & 43 & $<.001$ & .056 & $.036-.075$ & - & .29 & .930 & - \\
\hline Women & 105.35 & 43 & $<.001$ & .069 & $.052-.085$ & - & .03 & .884 & - \\
\hline Configural & $x^{2}$ & $d f$ & p-value & RMSEA & $90 \% \mathrm{Cl}$ & $\Delta$ RMSEA & p-value ${ }^{1}$ & CFI & $\Delta \mathrm{CFI}$ \\
\hline Configural & 184.03 & 86 & $<.001$ & .063 & $.050-.076$ & - & .05 & .907 & - \\
\hline Metric & $x^{2}$ & $d f$ & p-value & RMSEA & $90 \% \mathrm{Cl}$ & $\Delta$ RMSEA & p-value ${ }^{1}$ & CFI & $\Delta \mathrm{CFI}$ \\
\hline Metric & 195.58 & 95 & $<.001$ & .061 & $.049-.073$ & .002 & .07 & .904 & .003 \\
\hline Scalar & $x^{2}$ & $d f$ & p-value & RMSEA & $90 \% \mathrm{Cl}$ & $\Delta$ RMSEA & p-value ${ }^{1}$ & CFI & $\Delta \mathrm{CFI}$ \\
\hline Scalar & 206.97 & 104 & $<.001$ & .059 & $.047-.070$ & .002 & .11 & .902 & .002 \\
\hline Strict & $x^{2}$ & $d f$ & p-value & RMSEA & $90 \% \mathrm{Cl}$ & $\triangle$ RMSEA & p-value ${ }^{1}$ & CFI & $\Delta \mathrm{CFI}$ \\
\hline Strict & 215.12 & 115 & $<.001$ & .055 & $.044-.066$ & .004 & .22 & .905 & .003 \\
\hline \multicolumn{10}{|c|}{$\begin{array}{l}\text { Note: } \mathrm{RMSEA}<.05=\text { good fit; RMSEA }<.08=\text { acceptable fit; } \mathrm{CFI}>.9=\text { acceptable fit; } \Delta \mathrm{CFI}<.010=\text { non-significant worsening of fit; } \\
\left.\triangle \mathrm{RMSEA}<.015=\text { non-significant worsening of fit; }{ }^{1} \mathrm{p} \text {-value assessing close fit (RMSEA }<.05\right)\end{array}$} \\
\hline
\end{tabular}

\section{Measurement invariance}

\section{Gender differences in social attunement}

Including all individuals that identified as either a man $(N=266)$ or woman $(N=308)$, results showed no difference between men (Subscale 1: $M=18.05, S D=4.98$; Full scale: $M=41.89, S D=8.08$ ) and women (Subscale 1: $M=17.72, S D=5.03$; Full scale: $M=40.85, S D=7.89)$ on subscale $1(t(572)=$ $.78, p=.44)$ and the full scale $(t(572)=1.56, p=.12)$. However, there was a small but significant difference between men and women on subscale two $(t(572)=2.44, p=.02)$, with men $(M=28.15, S D$ $=5.45)$ scoring higher than women $(M=27.06, S D=5.24)$.

\section{Measurement invariance to gender}

First, the fit of the 11-item 2-factor structure was assessed for both subgroups (men and women). Confirmatory factor analysis (CFA) showed that this structure fit similarly well in both groups, with the chi-square test also being significant in both groups, but other fit indices indicating acceptable to good fit (Table 5). Second, configural invariance was assessed using group CFA in which the number of factors and their pattern was kept equal across groups (Table 5). While the chi-square test was significant, other indices of model fit indicated acceptable to good fit and all factor loadings were significant. Third, metric invariance was assessed using group CFA in which the factor loadings were 
also kept equal across groups (Table 5 ). Results showed that the fit did not worsen significantly $(\Delta C F I$ $<.010 \& \triangle R M S E A<.015)$, indicative of acceptable metric invariance. Similar results were found for scalar invariance, in which intercepts were also kept equal across groups, and strict factorial invariance, in which residual variances were also kept equal across groups (Table 5).

\section{Convergent and divergent validity}

In line with expectations, we found either no association or a negative association between social attunement scores and the need for cognition (Table 6). Also, there was no association between the social attunement scores and non-social potency. However, conformity was positively associated with the social attunement scales. The pattern of the association between social attunement and the other social reward scales did not fully match our expectations. For the admiration and social scales, subscale 1 did not match expectations, but subscale 2 and the full scale did. Against expectations, SAQ scores were positively associated with the passivity scale (no association was expected) and SAQ scores were not associated with the pro-social interaction scale (positive association expected).

\begin{tabular}{|c|c|c|c|c|c|c|c|c|c|c|c|c|c|}
\hline \multicolumn{3}{|c|}{ Scale } & \multicolumn{3}{|c|}{ Subscale 1 - Cognition } & \multicolumn{3}{|c|}{ Subscale 2 - Behaviour } & \multicolumn{3}{|c|}{ Full SAQ } & \multicolumn{2}{|c|}{$\begin{array}{c}\text { Internal } \\
\text { consistency }\end{array}$} \\
\hline $\begin{array}{l}\text { Need for } \\
\text { cognition }\end{array}$ & $\operatorname{Exp}$ & $d f$ & $r$ & $p$ & Results & $r_{s}$ & $P$ & Results & $r$ & $p$ & Results & $\omega$ & $\alpha$ \\
\hline $\begin{array}{l}\text { Need for } \\
\text { cognition }\end{array}$ & ns & 193 & -.27 & $<.001$ & - & -.06 & .40 & ns & -.20 & $<.01$ & - & .86 & .86 \\
\hline Social reward & Exp & $d f$ & $r_{s}$ & $p$ & Results & $r_{s}$ & $P$ & Results & $r_{s}$ & $p$ & Results & $\omega$ & $\alpha$ \\
\hline Admiration & + & 193 & .06 & .38 & ns & .32 & $<.001$ & + & .24 & $<.001$ & + & .79 & .73 \\
\hline $\begin{array}{l}\text { Non-social } \\
\text { potency }\end{array}$ & ns & 193 & -.03 & .65 & ns & .14 & .05 & ns & .08 & .26 & ns & .67 & .63 \\
\hline Passivity & ns & 193 & .29 & $<.001$ & + & .26 & $<.001$ & + & .34 & $<.001$ & + & .83 & .83 \\
\hline $\begin{array}{l}\text { Pro-social } \\
\text { interaction }\end{array}$ & + & 193 & -.08 & .28 & ns & -.01 & .94 & ns & -.06 & .43 & ns & .69 & .68 \\
\hline Social & + & 193 & .05 & .47 & ns & .22 & $<.01$ & + & .18 & .01 & + & .40 & .29 \\
\hline Conformity & $\operatorname{Exp}$ & $d f$ & $r_{s}$ & $p$ & Results & $r_{s}$ & $P$ & Results & $r_{s}$ & $p$ & Results & $\omega$ & $\alpha$ \\
\hline Conformity & + & 201 & .16 & .02 & + & .31 & $<.001$ & + & .30 & $<.001$ & + & .43 & .41 \\
\hline
\end{tabular}




\section{Age, social attunement and alcohol consumption}

Looking at AUDIT, age, PPD and SAQ, age related negatively with AUDIT $\left(r_{s}=-.10, p=.02\right.$; Internal consistency: $\omega=.83, \alpha=.79)$ and SAQ $\left(r_{s}=-.21, p<.001\right.$; Internal consistency: $\omega=.74, \alpha=$. 74), and AUDIT related positively with PPD ( $r_{s}=.57, p<.001$; Internal consistency: $\left.\omega=.83, \alpha=.66\right)$. Furthermore, regression analysis showed that both SAQ score $(B=.09, p=.02)$ and the interaction between age and PPD $(B=-.34, p=.002)$ were predictive of AUDIT scores $(F(4,537)=60.35, p<.001$; $\left.R^{2}=.31 ; N=541\right)$. As can be seen in Figure 2 , it appears that higher SAQ related to lower AUDIT in young (Age: 16-19) individuals who reported lower levels of peer drinking (PPD: 0-5).

Furthermore, we found positive associations between SAQ score and all four motives for alcohol consumption measured with the DMQ: social $\left(r_{\mathrm{s}}=.24, p<.001\right.$; Internal consistency: $\omega=.88$, $\alpha=.86)$, conformity $\left(r_{s}=.36, p<.001\right.$; Internal consistency: $\left.\omega=.81, \alpha=.80\right)$, coping $\left(r_{s}=.26, p<.001\right.$; Internal consistency: $\omega=.80, \alpha=.79)$, and enhancement $\left(r_{\mathrm{s}}=.13, p=.002\right.$; Internal consistency: $\omega=$ $.84, \alpha=.82$ ). Exploratory additional regression models were run to assess whether social and

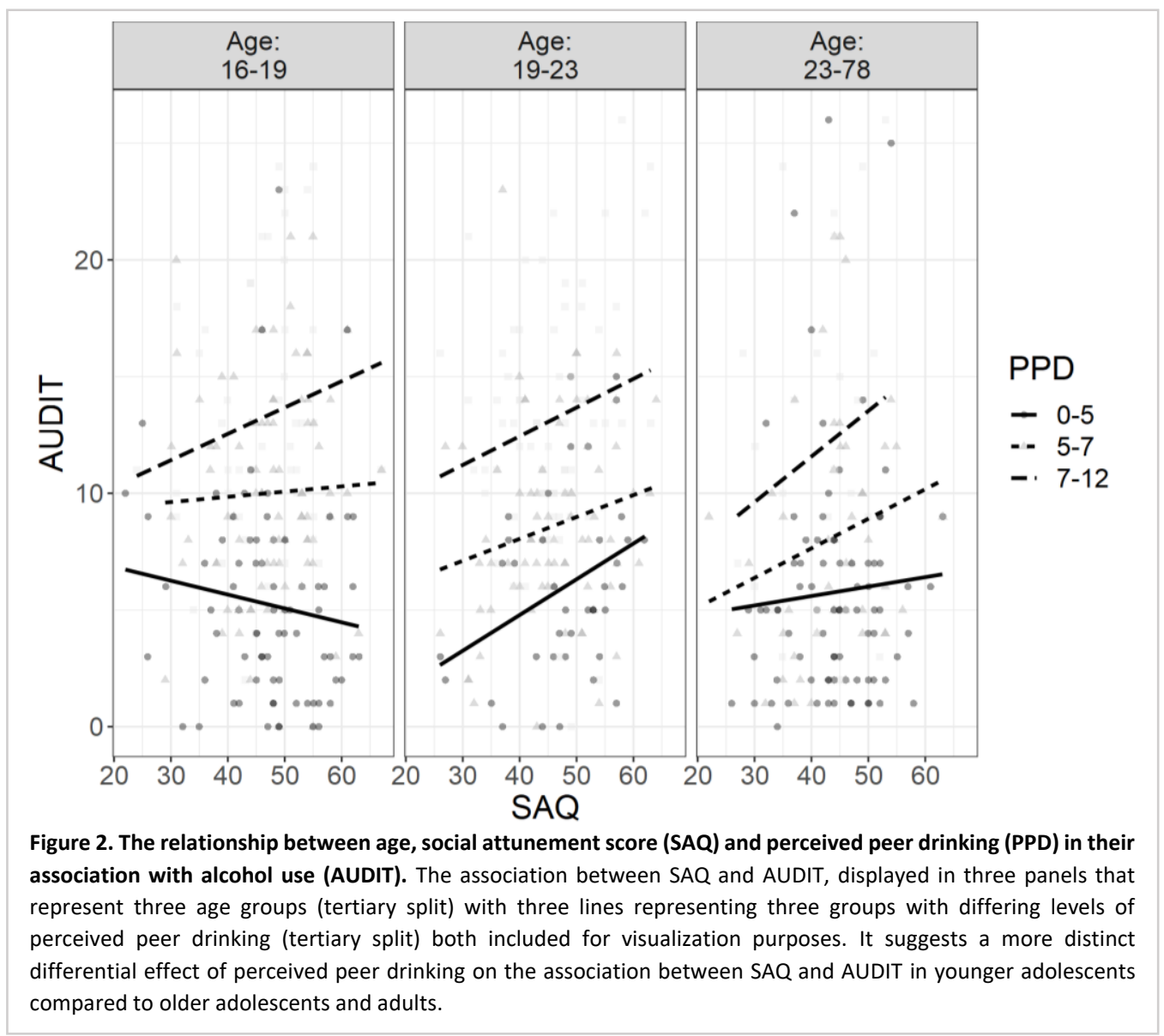


conformity drinking motives (separately) would explain additional variance in the regression model presented above. Results showed that, when adding conformity motives to the model $(F(5,525)=$ 45.11, $\left.p<.001 ; R^{2}=.30 ; N=525\right)$, the interaction between PPD and age remained a significant predictor of AUDIT ( $B=-.32, p=.004)$, but that this was not the case for SAQ $(B=.07, p=.07)$ and conformity $(B=.05, p=.21)$. When adding social motives to the model $\left(F(5,525)=58.57, p<.001 ; R^{2}\right.$ $=.35 ; N=525)$, the interaction between PPD and age also remained a significant predictor of AUDIT $(B=-.25, p=.02)$, while this was not the case for SAQ $(B=.03, p=.37)$. However, social motives were a significant predictor of AUDIT ( $B=.28, p<.001)$ in this model.

\section{Discussion}

The social attunement questionnaire (SAQ) was developed to be able to assess social attunement, the extent to which one adapts to and harmonizes behaviour with the social environment (Cousijn et al., 2018), in different social situations. The resulting 11-item SAQ contained two subscales capturing the 'Cognition' (subscale 1) and 'Behaviour' (subscale 2) related to social attunement, showing good psychometric properties that were consistent over genders. Furthermore, results largely confirmed our expectations on how SAQ scores, together with perceived peer drinking and age could predict alcohol use. The pattern of results from the analyses assessing convergent and divergent validity generally confirmed a good fit between the 11-item SAQ and our conceptual framework of social attunement but also provided novel insights to be tested in future studies. Below we will first discuss the structure and psychometric properties of the $S A Q$, followed by an in-depth discussion of theoretical and practical research implications.

The five items included in the 'Cognition' subscale (subscale 1) assess the extent to which you think about your own behaviour and how others perceive your behaviour. The six items included in the 'Behaviour' subscale (subscale 2) assess the actual behaviour someone performs in response to their environment to adapt to and harmonize with this environment. The 15 deleted items primarily included examples of cognitions and behaviours that are also reflected in the remaining items, suggesting that these items did not generalize well enough over individuals to be included in the SAQ. 
The structure that resulted from our exploratory factor analysis (EFA) was confirmed using confirmatory factor analysis (CFA) in another sample, that varied from the first sample on all included variables (Table 1). Notably, both the EFA and CFA showed significant chi-square tests, which indicates poor fit (Sun, 2005). However, it is well-known that chi-square tests of fit can be overly sensitive when the sample size is relatively large (e.g. Bollen, 1989; Miles \& Shevlin, 2007; Tucker \& Lewis, 1973) and other fit indices indicated acceptable to good fit in both analyses (Sun, 2005). In both samples separately, the internal consistency of the SAQ was moderate-acceptable, and in the samples combined, internal consistency was acceptable-good (Lance, Butts, \& Michels, 2006; Tavakol \& Dennick, 2011). In addition, the assessment of different measures of measurement invariance confirmed invariance to gender in this sample.

In line with our conceptional framework of social attunement, the 'Cognition' but not the 'Behaviour' subscale correlated negatively with the need for cognition scale, suggesting a cognitive component that differentiates between more subjective social cognition (e.g. "I try to prevent people from thinking that I am different.") and the more objective cognitive processes as assessed with the need for cognition questionnaire (e.g. "I really enjoy a task that involves coming up with new solutions to problems"; Cacioppo \& Petty, 1982; Verplanken et al., 1992). Furthermore, the 'Behaviour' but not the 'Cognition' subscale correlated positively with the social and admiration scale of the social reward questionnaire. The behaviour assessed by the social and admiration scales of the social reward questionnaire might indeed be similar to some of the behaviours assessed by the 'Behaviour' scale of the SAQ (e.g. "I try to align myself as good as possible to the group I'm with."). However, the cognitive process behind these behaviours might be very dissimilar, explaining the differences in associations and highlighting the importance of the 'Cognition' scale to capture the full social attunement process. As expected, conformity (negative reinforcement) and social attunement (positive reinforcement) correlated positively, but substantial SAQ variance cannot be explained by conformity (highest $r=.31$ for the behaviour subscale). 
In contrast to our expectations, the SAQ correlated positively with passivity ("giving others control and allowing them to make decisions"; Foulkes et al., 2014) but not with pro-social interaction ("having kind, reciprocal relations"; Foulkes et al., 2014) of the social reward questionnaire. However, speculatively, more passive individuals may score higher on social attunement because they more often adapt to others rather than deciding for themselves. The lack of association between the SAQ and pro-social interaction subscale of the social reward questionnaire, was also unexpected. This latter subscale focuses on the nature and type of relationships. While we expected that individuals with relatively more "kind, reciprocal relationships" would score higher on social attunement, our results suggest that the nature or the type of relationships does not directly affect social attunement to the individuals within this relationship.

We assessed how the SAQ related to drinking motives. Unexpectedly, the SAQ correlated positively with all drinking motives, a result that could not be explained by general higher alcohol consumption in individuals with higher social attunement scores. Importantly, while social and conformity drinking motives are intuitively more 'social' than enhancement and coping motives, the drinking motives questionnaire does not distinguish between the (social) settings in which drinking occurs (Cooper, 1994). Social factors could play a role in all drinking motives. For example, some may specifically drink to enhance positive affect in social settings (e.g. party) or to cope with negative affect during social situations, while others would drink to enhance positive affect or cope with negative affect in non-social settings (e.g. drinking alone). The positive association between the SAQ and all drinking motives, supported by the general notion that trajectories of alcohol use are more problematic in non-social versus social drinkers (e.g. Crutzen, Kuntsche, \& Schelleman-offermans, 2013; Kuntsche, Knibbe, Gmel, \& Engels, 2006; Mann, Chassin, \& Sher, 1987), suggest that it could also be useful to develop a drinking motives questionnaire that distinguishes between drinking in social and non-social settings. We would hypothesize that specifically non-social coping and enhancement will be negatively associated with social attunement and be a risk factor for long term 
problems, while social coping and enhancement would be positively associated with social attunement and could be indicative of a higher chance of maturing out.

In line with the general theories of social development (Steinberg, 2005), social attunement was highest in adolescents and significantly decreased with age. Also, those with higher perceived peer drinking consumed more alcohol themselves, while no direct association between social attunement and alcohol use was found. However, further analysis revealed that perceived peer drinking and age interacted and, together with social attunement were predictive of alcohol use. These results indicate that higher social attunement is associated with higher alcohol use in those individuals who perceive high peer drinking, but that the effect of peer drinking decreases with increasing age. This is in line with the idea that peers could be particularly influential during adolescence (e.g. Gardner \& Steinberg, 2005). However, it is important to note that the age distribution was skewed towards younger participants, and longitudinal data is needed to further investigate the development of social attunement with age, and its effect, as well as the effect of perceived peer drinking, on alcohol use across multiple age groups.

As there were positive associations between SAQ and both social drinking motives (social and conformity), we assessed whether the predictive effects of $S A Q$, peer drinking and age on alcohol use remained similar when including these drinking motives as predictors. Results showed that social drinking motives explained variance in alcohol use while accounting for the interaction between age and perceived peer drinking, while social attunement was not a significant predictor in this model. Adding conformity drinking motives to the model resulted in the interaction between age and perceived peer drinking to be the only significant predictor of alcohol use. However, it should be noted that the relatively high correlation of SAQ scores with both motives warrant careful interpretation. So, while social drinking motives also appear to explain additional variance in the association of age and perceived peer drinking with alcohol use, the strength of the SAQ is that it can be used to assess social attunement in both alcohol-use-related as well as more general settings, while this is not the case for 
the measures of drinking motives. Further studies, in a broader range of settings, are needed to assess the utility of the SAQ.

Aside from studying developmental trajectories of the $S A Q$, the range of social settings (e.g. different substances or different groups of individuals to attune to) in which the SAQ could be used, and the association of the SAQ with other types of social behaviour, several additional steps should be taken to assess the validity of the SAQ. The current study only collected limited demographic data from participants and future studies should collect a wider range of variables to assess measurement invariance to for example SES, ethnicity, and educational level. Moreover, assessments of test-retest reliability are needed, as well as translations of the SAQ to test the validity beyond our Dutch setting. In conclusion, the two subscales of the SAQ appear to capture both the "Cognition" and "Behaviour" components of social attunement, showing good measurement invariance to gender. Our newly developed instrument appears to be suitable to gain important insights into the role of social attunement in development and substance use, however, more studies are needed to test the SAQ's utility in broader samples and situations. 


\section{References}

Bollen, K. A. (1989). A New Incremental Fit Index for General Structural Equation Models. Sociological Methods \& Research, 17(3), 303-316.

Brooks-Russell, A., Simons-Morton, B., Haynie, D., Farhat, T., \& Wang, J. (2014). Longitudinal Relationship Between Drinking with Peers, Descriptive Norms, and Adolescent Alcohol Use. Prevention Science, 15(4), 497-505. https://doi.org/10.1007/s11121-013-0391-9

Cacioppo, J. T., \& Petty, R. E. (1982). The need for cognition. Journal of Personality and Social Psychology, 42(1), 116-131. https://doi.org/10.1037/0022-3514.42.1.116

Casey, B. J., Jones, R. M., \& Hare, T. A. (2008). The adolescent brain. Annals of the New York Academy of Sciences, 1124, 111-126. https://doi.org/10.1196/annals.1440.010

Chassin, L., Flora, D. B., \& King, K. M. (2004). Trajectories of alcohol and drug use and dependence from adolescence to adulthood: The effects of familial alcoholism and personality. Journal of Abnormal Psychology, 113(4), 483-498. https://doi.org/10.1037/0021-843X.113.4.483

Cooper, M. L. (1994). Motivations for alcohol use among adolescents: Development and validation of a four-factor model. Psychological Assessment, 6(2), 117-128. https://doi.org/10.1037/10403590.6.2.117

Cousijn, J., Luijten, M., \& Feldstein Ewing, S. W. (2018). Adolescent resilience to addiction: a social plasticity hypothesis. The Lancet Child and Adolescent Health, 2(1), 69-78. https://doi.org/10.1016/S2352-4642(17)30148-7

Crone, E. A., \& Dahl, R. E. (2012). Understanding adolescence as a period of social-affective engagement and goal flexibility. Nature Reviews Neuroscience, 13(9), 636-650. https://doi.org/10.1038/nrn3313

Crutzen, R., Kuntsche, E., \& Schelleman-offermans, K. (2013). Drinking Motives and Drinking Behavior Over Time : A Full Cross-Lagged Panel Study Among Adults, 27(1), 197-201. https://doi.org/10.1037/a0029824

Dawson, D. A., Grant, B. F., Stinson, F. S., \& Chou, P. S. (2006). Maturing out of alcohol dependence: 
The impact of transitional life events. Journal of Studies on Alcohol, 67(2), 195-203.

https://doi.org/10.15288/jsa.2006.67.195

Foulkes, L., Viding, E., McCrory, E., \& Neumann, C. S. (2014). Social Reward Questionnaire (SRQ):

Development and validation. Frontiers in Psychology, 5(MAR), 1-8.

https://doi.org/10.3389/fpsyg.2014.00201

Gardner, M., \& Steinberg, L. (2005). Peer influence on risk taking, risk preference, and risky decision making in adolescence and adulthood: An experimental study. Developmental Psychology, 41(4), 625-635. https://doi.org/10.1037/0012-1649.41.4.625

Gladwin, T. E., Figner, B., Crone, E. A., \& Wiers, R. W. (2011). Addiction, adolescence, and the integration of control and motivation. Developmental Cognitive Neuroscience, 1(4), 364-376. https://doi.org/10.1016/j.dcn.2011.06.008

Hayes, A. F., \& Coutts, J. J. (2020). Use Omega Rather than Cronbach's Alpha for Estimating Reliability. But.... Communication Methods and Measures, 14(1), 1-24. https://doi.org/10.1080/19312458.2020.1718629

Heyman, G. M. (2009). Addiction: a disorder of choice. Cambridge, MA: Harvard University Press. Jackson, K. M., Sher, K. J., Gotham, H. J., \& Wood, P. K. (2001). Transitioning into and out of largeeffect drinking in young adulthood. Journal of Abnormal Psychology, 110(3), 378-391.

JASP Team. (2020). JASP (Version 0.14.1).

Kuntsche, E., Knibbe, R., Gmel, G., \& Engels, R. (2006). 'I DRINK SPIRITS TO GET DRUNK AND BLOCK OUT MY PROBLEMS ...' BEVERAGE PREFERENCE , DRINKING MOTIVES AND ALCOHOL USE IN ADOLESCENCE, 41(5), 566-573. https://doi.org/10.1093/alcalc/agl046

Lance, C. E., Butts, M. M., \& Michels, L. C. (2006). What Did They Really Say ? Organizational Research Methods, 9(2), 202-220.

Leary, M. R., Kelly, K. M., Cottrell, C. A., \& Schreindorfer, L. S. (2013). Construct validity of the need to belong scale: Mapping the nomological network. Journal of Personality Assessment, 95(6), 610-624. https://doi.org/10.1080/00223891.2013.819511 
Lee, M. R., Ellingson, J. M., \& Sher, K. J. (2015). Integrating Social-Contextual and Intrapersonal Mechanisms of "Maturing Out": Joint Influences of Familial-Role Transitions and Personality Maturation on Problem-Drinking Reductions. Alcoholism: Clinical and Experimental Research, 39(9), 1775-1787. https://doi.org/10.1111/acer.12816

Lennox, R. D., \& Wolfe, R. N. (1984). Revision of the self-monitoring scale. Journal of Personality and Social Psychology, 46(6), 1349-1364. Retrieved from https://psycnet.apa.org/record/198427678-001?doi=1

MacPherson, L., Magidson, J. F., Reynolds, E. K., Kahler, C. W., \& Lejuez, C. W. (2010). Changes in sensation seeking and risk-taking propensity predict increases in alcohol use among early adolescents. Alcoholism: Clinical and Experimental Research, 34(8), 1400-1408.

https://doi.org/10.1111/j.1530-0277.2010.01223.x

Mann, L. M., Chassin, L., \& Sher, K. J. (1987). Alcohol Expectancies and the Risk for Alcoholism Assessing Risk for Future Alcohol Abuse : Family, 55(3).

Mark Snyder, \& Steve Grangestad. (1986). On the Nature of Self-Monitoring: Matters of Assessment, Matters of Validity. Journal of Personality and Social Psychology, 51(1), 125-139. Retrieved from http://psycnet.apa.org/journals/psp/51/1/125/

Marshal, M. P., \& Chassin, L. (2000). Parental , Sibling, and Peer Influences on Adolescent Substance Use and Alcohol Problems Parental, Sibling, and Peer Influences on Adolescent Substance Use and Alcohol Problems. Applied Developmental Science, 4(2), 80-88.

https://doi.org/10.1207/S1532480XADS0402

Mehrabian, A., \& Stefl, C. A. (1995). Basic Temperament Components of Loneliness, Shyness, and Conformity. Social Behavior and Personality: An International Journal. https://doi.org/10.2224/sbp.1995.23.3.253

Miles, J., \& Shevlin, M. (2007). A time and a place for incremental fit indices. Personality and Individual Differences, 42(5), 869-874. https://doi.org/10.1016/j.paid.2006.09.022

Orford, J. (2001). Addiction as excessive appetite. Addiction, 96(1), 15-31. 
https://doi.org/10.1046/j.1360-0443.2001.961152.x

Polit, D. F., \& Beck, C. T. (2006). The content validity index: Are you sure you know what's being reported? critique and recommendations. Research in Nursing \& Health, 29(5), 489-497. https://doi.org/10.1002/nur.20147

Santor, D. A., Messervey, D., \& Kusumakar, V. (2000). Measuring peer pressure, popularity, and conformity in adolescent boys and girls: Predicting school performance, sexual attitudes, and substance abuse. Journal of Youth and Adolescence, 29(2), 163-182.

https://doi.org/10.1023/A:1005152515264

Saunders, J. B., Aasland, O. G., Babor, T. F., De la Fuente, J. R., \& Grant, M. (1993). Development of the Alcohol Use Disorders Identification Test (AUDIT): WHO Collaborative Project on Early Detection of Persons with Harmful Alcohol Consumption-II. Addiction, 88(6), 791-804. https://doi.org/10.1111/j.1360-0443.1993.tb02093.x

Sebastian, C., Burnett, S., \& Blakemore, S. J. (2008). Development of the self-concept during adolescence. Trends in Cognitive Sciences, 12(11), 441-446.

https://doi.org/10.1016/j.tics.2008.07.008

Steinberg, L. (2005). Cognitive and affective development in adolescence, 9(2).

https://doi.org/10.1016/j.tics.2004.12.005

Sun, J. (2005). Assessing goodness of fit in confirmatory factor analysis. Measurement and Evaluation in Counseling and Development, 37(4), 240-256.

https://doi.org/10.1080/07481756.2005.11909764

Taber, K. S. (2018). The Use of Cronbach's Alpha When Developing and Reporting Research Instruments in Science Education. Research in Science Education, 48(6), 1273-1296. https://doi.org/10.1007/s11165-016-9602-2

Tavakol, M., \& Dennick, R. (2011). Making sense of Cronbach's alpha. International Journal of Medical Education, 2, 53-55. https://doi.org/10.5116/ijme.4dfb.8dfd

Teunissen, H. A., Spijkerman, R., Prinstein, M. J., Cohen, G. L., Engels, R. C. M. E., \& Scholte, R. H. J. 
(2012). Adolescents' Conformity to Their Peers' Pro-Alcohol and Anti-Alcohol Norms: The Power of Popularity. Alcoholism: Clinical and Experimental Research, 36(7), 1257-1267. https://doi.org/10.1111/j.1530-0277.2011.01728.x

Tucker, L. R., \& Lewis, C. (1973). A reliability coefficient for maximum likelihood factor analysis. Psychometrika, 38(1), 1-10.

Vergés, A., Haeny, A. M., Jackson, K. M., Bucholz, K. K., Grant, J. D., Trull, T. J., ... Sher, K. J. (2013). Refining the notion of maturing out: Results from the national epidemiologic survey on alcohol and related conditions. American Journal of Public Health, 103(12), 67-73. https://doi.org/10.2105/AJPH.2013.301358

Verplanken, B., Hazenberg, P. T., \& Palenéwen, G. R. (1992). Need for cognition and external information search effort. Journal of Research in Personality, 26(2), 128-136.

https://doi.org/10.1016/0092-6566(92)90049-A 